\title{
Puberty associated micro anatomical modification in testes and epididymis of Teddy goat (Capra hircus)
}

\author{
Shujat Ali Khan ${ }^{1}$, Illahi Bux Kalhoro ${ }^{1}$, Jameel Ahmed Gandahi ${ }^{1}$, \\ Waseem Ali Vistro ${ }^{*}$, Qudratullah Kalwer ${ }^{2,3}$, Imtiaz Ali ${ }^{1}$, Tarique \\ Ahmed Khokhar ${ }^{3}$ and Mazhar Hussain Mangi ${ }^{1}$ \\ 1. Faculty of Animal husbandry and Veterinary Science, Sindh Agriculture University Tandojam-Pakistan \\ 2. China Academy of Agriculture Sciences-China \\ 3. Shaheed Benazir Bhutto University of veterinary and animal sciences Sakrand, Sindh-Pakistan \\ *Corresponding author's email: drwaseemvistro@gmail.com \\ Citation
}

Shujat Ali Khan, Illahi Bux Kalhoro, Jameel Ahmed Gandahi, Waseem Ali Vistro, Qudratullah Kalwer, Imtiaz Ali, Tarique Ahmed Khokhar and Mazhar Hussain Mangi. Puberty associated micro anatomical modification in testes and epididymis of Teddy goat (Capra hircus). Pure and Applied Biology. Vol. 8, Issue 2, pp1281-1286. http://dx.doi.org/10.19045/bspab.2019.80070

\begin{tabular}{llll}
\hline \hline Received: 26/12/2018 & Revised: 30/03/2019 & Accepted: 05/04/2019 & Online First: 10/04/2019 \\
\hline \hline
\end{tabular}

\section{Abstract}

Despite some studies being conducted over past few decades, puberty associated histological changes in testes and epididymis of caprine is still largely unknown. The present study was conducted to evaluate the microanatomy of the testicles and epididymis through light microscope. Histometric parameters of testes and epididymis were measured through software Image J. Majority of seminiferous tubules (ST) become rounded in shape, increased parenchymal cells and space between them was increased in pubertal stage. In ST, peritubular cells, Sertoli cells and developing undifferentiated germinal cells were present at pubertal stage. In pre-pubertal stage the epididymal duct was lined by non-ciliated epithelium and become ciliated in pubertal stage. Luminal diameter of the tubules increased from pre-pubertal to pubertal stage in the tail region. The abundant loose connective tissue was observed in prepubertal as compared with pubertal stage. The values of histometerical parameters; diameter of seminiferous tubules, thickness of tunica albugenia, diameter of caput of epididymis tubule, corpus of epididymis tubule and cauda of epididymal tubules were significantly higher in pubertal stage than pre-pubertal stage of Teddy goat. Based on above findings it is concluded that puberty and age significantly affects micro anatomical aspects of reproductive organs of Teddy goats.

Keywords: Epididymis; Microanatomy; Testes; Teddy goat

\section{Introduction}

In Pakistan goats are reared for milk and meat purposes, mainly classified as in milch and meat categories. Teddy goat is one of the famous breed of Pakistan [1]. Puberty is sexual development stage, at which animals are started to reproduction [2]. Meanwhile, African-type goats like Red Sokoto and Borno white, breeding take place early, sexual maturity being reached after six months of age [3]. In contrast, in tropical areas goats reach at sexual maturity as early in three months of age [4].

Testicles are vital organ in male reproductive system which play both endocrine (secrete testosterone hormone) and exocrine (secrete sperm) function. Histologically, the testis of goat are 
enclosed in a testicular tissue capsule through which blood vessels and nerves arrive and depart the substance of the organ. Testis is composed of three layers, such as tunica vaginalis, tunica albuginea and tunica vasculosa [5]. In certain mammals, the existence of smooth muscle cells in the testicular capsule, the contraction of which may support in moving immovable spermatozoa into the duct system [6]. The testicular capsule has been found to respond, by contraction, to various chemical and electrical stimulations [7]. Peritubular tissue (tunica or lamina propria) that capitalizes the seminiferous tubules is present in all mammal species [8].

The mammalian epididymis is an elongated tube where sperm get maturation. The epididymis is divided into three distinct parts head (caput), body (carpus) and tail (cauda) [9]. The body of epididymis is attached with the lateral surface of testicle [10]. Whereas, head and body are involved in sperm maturation and tail is place for sperm storage [11]. Various studies [12, 13] have exposed that spermatogenesis in rams is sensitive to increments in protein ingestion. This effect has been associated with an increase in testicular size as reflecting an increase in the volume of the seminiferous epithelium and in the diameter of the somniferous tubules [14]; thus, the size of the testis is directly related to the potential of sperm production. In the case of rams, changes in body weight are directly associated with testicular growth and regression [15]. However, there is scanty literature available concerned histological change in testes and epididymis in different age groups of Teddy goat.

The present study was conducted to significant changes in the testicles and epididymis during pre-pubertal and pubertal stage of Teddy goat.

\section{Materials and methods}

\section{Animals}

Twenty Teddy goats were divided in to two equal groups. Group A $(n=10)$ male goats age from 3-7 months and group $B(n=10)$ age from 12-24 months. Animals were reared in animal house of Faculty of animal husbandry and veterinary science, Sindh agriculture university Tandojam.

\section{Collection of samples}

The tissue samples were collected from each Teddy goat immediately after slaughter and immersed in Bouin's solution for histological studies.

\section{Histological analysis}

The testis and epididymis samples were placed in 10\% neutral buffered formalin for fixation overnight, and then embedded in paraffin wax. Sectioning was done at $5 \mu \mathrm{m}$. these sections were dehydrated in alcohol grading series (100-75\%) for 2 mint in each alcohol grade. These sections were stained with hematoxylin and eosin procedures (Harrys hematoxylin for $2 \mathrm{~min}$ and $1 \%$ eosin for $30 \mathrm{sec}$ ). For light microscopy analysis using an Olympus microscope (BX53), camera (Olympus DP73) [16].

\section{Statistical analysis}

The histomorphometric analysis of tissue stained sections were measured by the Image $\mathbf{J}$ software and analyzed statistically with GraphPad Prism 7.0. Results were presented as mean \pm SEM. The statistical significance of differences among the mean was also analyzed by t-test $(P<0.05)$.

\section{Results}

Micro anatomical changes in testes during pre-pubertal and pubertal stages Light microscopy revealed that the testicles of Teddy goat were enclosed by a capsule through which blood vessels; nerves enter and permit the substance of organ. Testes was composed of three layers, tunica vaginalis, which was derived from the peritoneum, the middle or thickest layer was tunica albuginea and the innermost and often poorly distinguished layer was the tunica vasculosa. Inside to the capsule various shapes of seminiferous tubules were present like comma, elongated, oval, elliptical and straight which were densely packed in the pre-pubertal testis. Single layer parenchymal cells were present in the pre-pubertal testis. The epithelium of seminiferous tubule was stratified 
containing Sertoli cells (Figure 1A). Majority of seminiferous tubules become rounded in shape, increased parenchymal cells and space between them also increased in pubertal stage. From the tunica albugenia number of connective tissue septae in the form of trabaculae was arise separated the parenchyma of testis to form number of hexagonal shaped compartments (Figure 1B). Elongation of mature sperms was observed within the lumen of seminiferous tubules. The Leydig cells or interstitial cells were present in between seminiferous tubules. In the seminiferous tubules peritubular cells, Sertoli cells and developing undifferentiated germinal cells were present at pubertal stage (Figure 1C).

Micro-anatomical changes in epididymis during pre-pubertal and pubertal stages The epididymis is a folded epithelial tube and highly organized structure comprised of head, body and tail regions. In prepubertal stage the epididymal duct was lined by non-ciliated epithelium and become ciliated in pubertal stage (Figure 2A \& B). Regional histological variations were noticed in the organ. The ciliated pseudo stratified columnar epithelium gradually decreased from the beginning of head to tail in both age groups. The tubules and inter-tubular area of epididymis consisted of the loose connective tissue. The smooth muscle fibers were surrounded the epithelium and their thickness increased proximal-distally. The sperm contents were observed on the periphery and increased throughout the lumen of tubules of the body region of epididymis (Figure $3 \mathrm{~A} \& \mathrm{~B}$ ). Tunica serosa and tunica muscularis was prominent in the tail region in pre-pubertal stage. Luminal diameter of the tubules increased from pre-pubertal to pubertal stage in the tail region. The abundant loose connective tissue was observed in prepubertal as compared with pubertal stage (Figure 4A \& B).

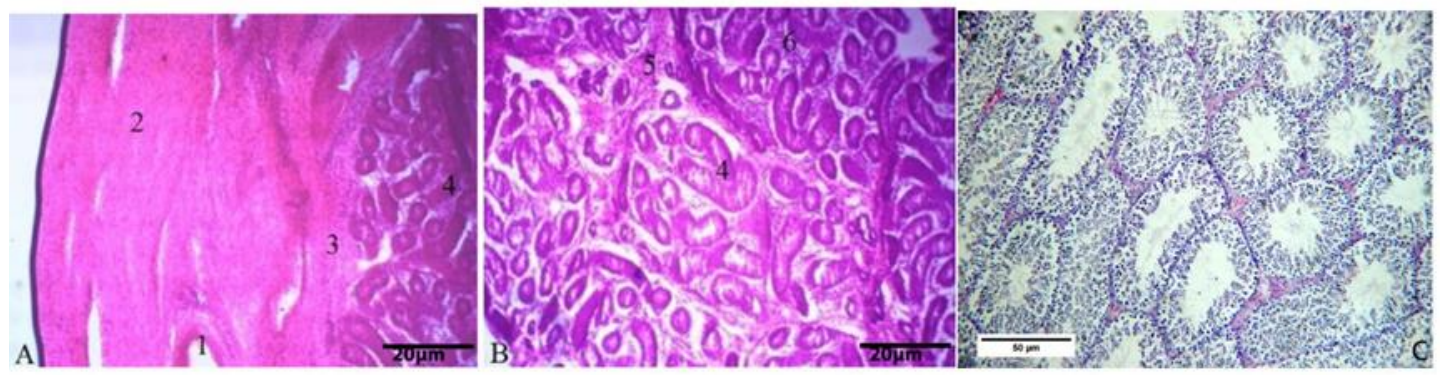

Figure 1. Microanatomy of testicles of Prepubertal (A) and Pubertal (B\&C) goat. A \& B (H\&E, 20X) \& C (H\&E, 50X) 1: Blood vessel 2: Capsule (Tunica albugina) 3: Tunica vasculosa 4: Seminiferous tubules 5: Trabaculae 6: Leydig cells 7: Peritubular cells 8: Sertoli cells 9: Sperm contents

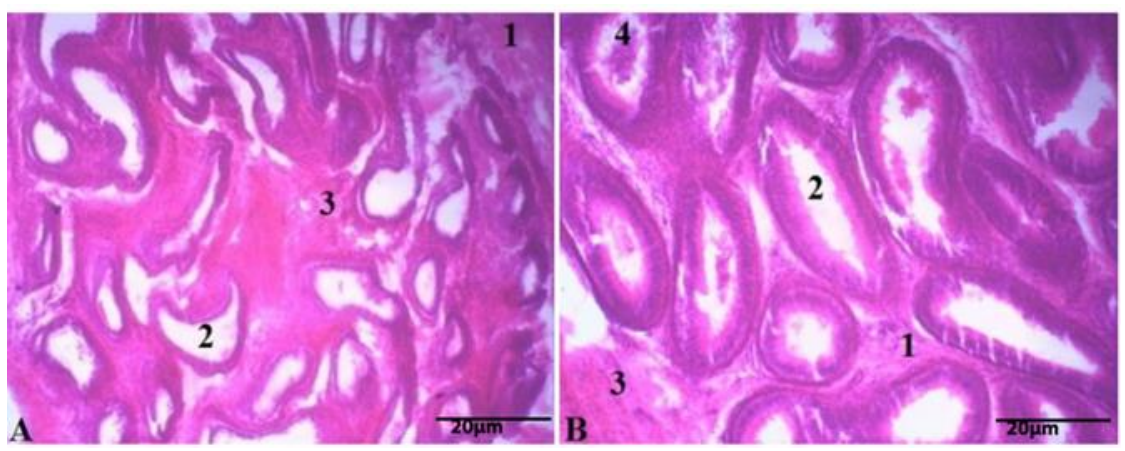

Figure 2. Microanatomy of caput-epididymis of Pre-pubertal (A) and pubertal (B) goat. 1: Smooth muscle fibers 2: Lumen 3: Loose connective tissue 4: Sperm content (H\&E, 20X) 


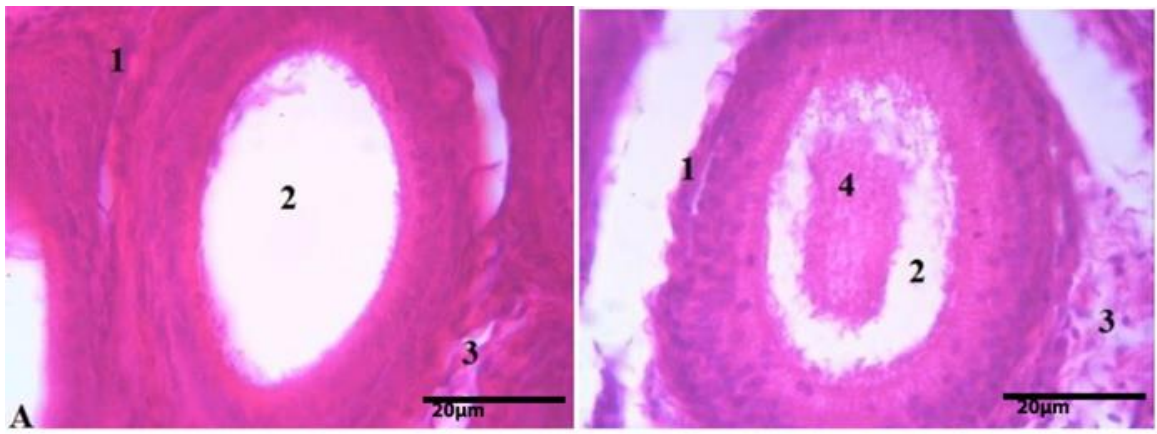

Figure 3. Microanatomy of corpus-epididymis of Pre-pubertal (A) and pubertal (B) goat. 1: Smooth muscle fibers 2: Lumen 3: Loose connective tissue 4: Sperm content (H\&E, 20X)

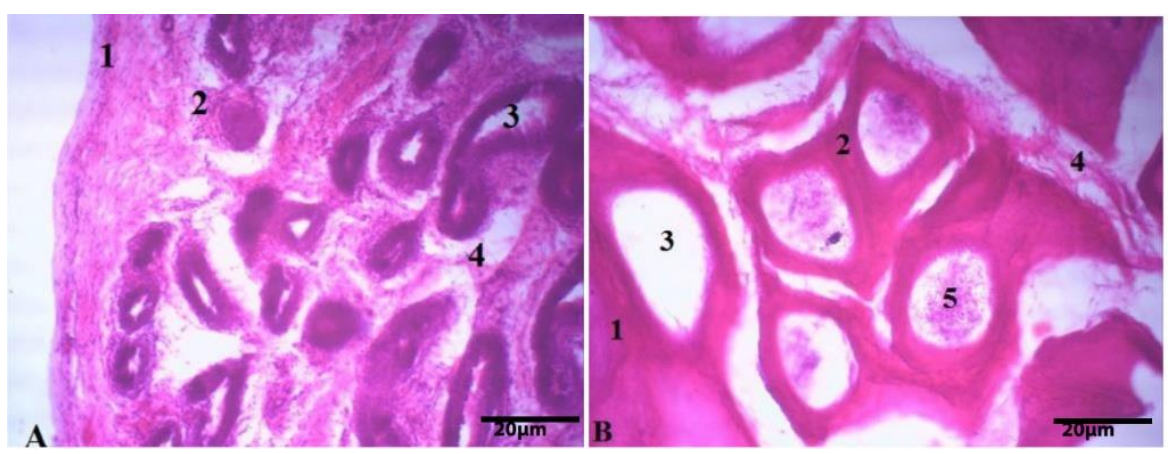

Figurer 4. Microanatomy of cauda-epididymis of Pre-pubertal (A) and pubertal (B) goat. 1: Serosa 2: Circular smooth muscle 3: Lumen 4: Loose connective tissue 5: Sperm content (H\&E, 20X)

Histometery of testes and epididymis

The mean values of histometerical parameters including the thickness of capsule (tunica albugenia), diameter of seminiferous tubules, , diameter of caput of epididymis tubule, corpus of epididymis tubule and cauda of epididymis tubule were significantly $(\mathrm{P}<0.05)$ higher in pubertal stage as compared to pre-pubertal stage . The histological parameters were shown in (Table 1).

Table 1. Histometery of testes and epididymis

\begin{tabular}{|c|c|c|}
\hline Parameters & A. Pre-pubertal $(\boldsymbol{\mu m})$ & B. Pubertal $(\boldsymbol{\mu m})$ \\
\hline Thickness of capsule (tunica albugenia) & $265.20 \pm 9.41$ & $402.84 \pm 6.62$ \\
\hline Diameter of somniferous tubules & $71.076 \pm 8.085$ & $181.55 \pm 5.084$ \\
\hline Diameter of caput-epididymis tubule & $83.34 \pm 7.46$ & $253.86 \pm 4.70$ \\
\hline Diameter of corpus-epididymis tubule & $54.00 \pm 6.016$ & $143.29 \pm 13.59$ \\
\hline Diameter of cauda-epididymis tubule & $180.63 \pm 9.17$ & $379.19 \pm 7.74$ \\
\hline
\end{tabular}

\section{Discussion}

To our knowledge, this is the first report to evaluate the micro anatomical changes and histometric alternation in testes and epididymis of Teddy goat. Previous studies reported $[17,18]$ only on histology of reproductive system of different domestic animals, nevertheless the information about microanatomy of Testicle pre- pubertal and pubertal male Teddy goats are unavailable. In the present study the testes of Teddy goat were enclosed in a testicular tissue capsule through which blood vessels and nerves enter and leave the substance of the organ. It was composed of three layers, outermost the tunica vaginalis, which was derived from the peritoneum, the middle and by far the thickest layer was the tunica 
albuginea and the innermost and often poorly differentiated layer was the tunica vasculosa. Same finding are shown by [19] in male goats and [17] in Gaddi goats.

Present study revealed that, the mean diameter of seminiferous tubules was $71.08 \pm 8.08$ and $181.55 \pm 5.08 \mu \mathrm{m}$ in group $A$ and $B$ respectively. [10] Reported that the diameter of somniferous tubules are increased, 71.00 to $231.7 \mu \mathrm{m}$ in bucks with advancement of age. As well as , [19] recorded the diameter of seminiferous tubules in Japanese native goat, the diameter increased from $133 \pm 9.9 \mu \mathrm{m}$ at three months to $198 \pm 1.0 \mu \mathrm{m}$ at six months of age.

In our current study, thickness of tunica albugenia was 265.20 \pm 9.41 and $402.84 \pm 6.62 \mu \mathrm{m}$ in $\mathrm{A}$ and $\mathrm{B}$ group respectively. [3] Observed the mean thickness of tunica albugenia is $264.9 \pm 5.6$ and $402.3 \pm 5.6 \mu \mathrm{m}$ in pre-pubertal and pubertal stages. [20] Reported a fibro muscular capsule of testes resembling the tunica albuginea, which measured $105 \mu \mathrm{m}$ at birth and $125 \mu \mathrm{m}$ at 6 months in old Beetal goats. [21] Recorded a very thin tunica albuginea $33.02 \pm 2.34 \mu \mathrm{m}$ in Nagpuri goats. [19] Recorded in Gaddi goats it is $116 \mu \mathrm{m}$ at birth, $416 \mu \mathrm{m}$ in prepubertal, $616 \mu \mathrm{m}$ in pubertal and $697 \mu \mathrm{m}$ in post pubertal stages.

In the present study regional histological variations were observed from head to tail in the various segments of epididymis. The height of the principal columnar cells in the pseudo stratified ciliated columnar epithelium gradually decreased from the beginning of the head to the end of the tail [22]. The luminal region filled with the sperms was also observed in pubertal stage [23].

The tubular diameter of the epididymal tubules gradually increased from the beginning of the head to the end of the tail in both groups. In group A the diameter of caput-epididymal tubules, corpus and cauda were $83.34 \pm 7.45,54.04 \pm 6.01$ and $180.63 \pm 9.16 \mu \mathrm{m}$, respectively. While in group B it was as 253.86 \pm 4.69 ,
$143.29 \pm 13.59$ and $379.19 \pm 7.73 \mu \mathrm{m}$. This showed significant difference in the diameter as the age of bucks advanced. Age related increase of epididymis tubule (head, body and tail) was also noticed by [5] in Assam Goats.

\section{Conclusion}

Our study demonstrated that, the age significantly affects the micro anatomical aspects of the testicle and epididymis of Teddy male goats. These findings may help anatomists, pathologists and theriogenologists to develop a positive reception of micro anatomy of normal reproductive system of mammals.

\section{Authors' contributions}

Conceived and designed the experiments: SA Khan, IB Kalhoro \& JA Gandahi, Performed the experiments: SA Khan, I Tarique \& Q Kalwer, Analyzed the data: SA Khan, I Ahamd, TA Khokhar \& WA Vistro, Contributed reagents/ materials/ analysis tools: SA Khan, Y Liu \& Q Kalwer, Wrote the paper: SA Khan.

\section{References}

1. Kuthu Z, Javed K, Babar M, Sattar A \& Abdullah M (2013). Environmental effects on growth traits of Teddy goats. JAPS, J Ani and Plant Sci 23(3): 692698.

2. Bielli A, Katz H, Pedrana G, Gastel MaT, Moraña A, Castrillejo A \& Rodriguez-Martinez H (2001). Nutritional management during fetal and postnatal life, and the influence on testicular stereology and Sertoli cell numbers in Corriedale ram lambs. Small Ruminant Res 40(1): 63-71.

3. Baird RW \& Whitehead H (2000). Social organization of mammal-eating killer whales: group stability and dispersal patterns. Canadian J Zoo 78(12): 2096-2105.

4. Steele M (1996). The tropical agriculturalist: goats. The tropical agriculturalist: goats.

5. Davis JR, Langford GA \& Kirby PJ (1970). The testicular capsule. The Testis 1: 281-337. 
6. Hargrove JL, MacIndoe JH \& Ellis LC (1977). Testicular contractile cells and sperm transport. Fertility and Sterility 28(11): 1146-1157.

7. Banks FC, Knight GE, Calvert RC, Turmaine M, Thompson CS, Mikhailidis DP \& Burnstock G (2006). Smooth muscle and purinergic contraction of the human, rabbit, rat, and mouse testicular capsule. Bio of Repro 74(3): 473-480.

8. Maekawa M, Kamimura K \& Nagano $\mathrm{T}$ (1996). Peritubular myoid cells in the testis: their structure and function. Arch of Histol and Cytol 59(1): 1-13.

9. Bedford J (1975). Maturation transport and fate of spermatozoa in the epididymis.

10. Nimase R, Bhosle N, Desale R \& Deokar D (2009). Developmental histomorphology of testes in goat. Asian J Ani Sci 3(2): 116-119.

11. Cooper TG (1986). Epididymal Secretion and Resorption of Proteins the Epi, Sperm Matur and Fertilisation. Springer, pp 200-230.

12. Blache D, Chagas LM, Blackberry MA, Vercoe PE \& Martin GB (2000). Metabolic factors affecting the reproductive axis in male sheep. $J$ Repro and Fertility 120(1): 1-11.

13. Fourie P, Schwalbach L, Neser F \& Van der Westhuizen C (2004). Scrotal, testicular and semen characteristics of young Dorper rams managed under intensive and extensive conditions. Small Ruminant Res 54(1-2): 53-59.

14. Hötzel M, Markey C, Walkden-Brown S, Blackberry M \& Martin G (1998). Morphometric and endocrine analyses of the effects of nutrition on the testis of mature Merino rams. J Repro and Fertility 113(2): 217-230.
15. Murray PJ, Rowe J, Pethick D \& Adams N (1990). The effect of nutrition on testicular growth in the Merino ram. Austr J Agri Res 41(1): 185-195.

16. Bancroft JD \& Gamble M (2008). Theory and practice of histo techn: Elsevier Health Sciences.

17. Kabiraj SK, Hoque SM, Kh MY \& Husain SS (2011). Testicular biometry and its relationship with body weight and semen output of black Bengal bucks in Bangladesh. $J$ Cell and Ani Bio 5(2): 27-32.

18. Archana $P$, Katiyar R, Sharma D, Farooqui M \& Ajay P (2014). Postnatal Development of Testis in Gaddi Goat (Capra hircus). Inter J Morphol 32(1).

19. Mohammed AHS, Kadium DAH \& Ebed AK (2011). Some morphometric and histological description of the seminiferous, striaghted and rete testis tubules in the testis of indogenous male goats (two years old). Kufa J Vet Med Sci 2(1): 19-29.

20. Gupta AN (1989). Correlative Anatomy of the Testers, Epididymides and Accessory Sex Glands in Goat. Veterinary Anatomy, CCSHAU, Hisar.

21. Karmore S, Bhamburkar V, Dalvi R, Banubakode $\mathrm{S} \&$ Nandeshwar $\mathrm{N}$ (2003). Histomorphology of testis of goat (Capra hircus). Ind J Ani Sci (India).

22. Kishore $P$, Ramesh $G$ \& Basha $\mathrm{SH}$ (2012). Postnatal differentiation and regional histological variations in the ductus epididymidis of rams.

23. Sharma R, Goyal A \& Veena Y (2014). Histological Studies on Epididymis Region of Goat (Capra Hircus) Reproductive System. Inter J Pure and Appl Zoo 2(3): 224-227. 